\title{
CAPTIVE BREEDING AND ZOO POLICY IN INDIA - LESSONS FROM ARIGNAR ANNA ZOOLOGICAL PARK
}

\author{
Alyna Barat ${ }^{1,2}$ and G. Poyyamoli ${ }^{1}$ \\ ${ }^{1}$ Salim Ali School of Ecology \& Environmental Scienceas, Pondicherry University, Pondicherry 605014, India \\ ${ }^{2}$ Present address: 7/1, Tehmi Terrace, 805, Dr. B.A. Road, Dadar, Mumbai, Maharashtra 400014, India
}

\begin{abstract}
The objectives of the study conducted at the Arignar Anna Zoological Park, Chennai, Tamil Nadu, were to assess the success of captive breeding of chosen mammalian species and to evaluate the potential of the zoo for ex situ conservation. Results obtained showed that the potential of the zoo to conserve those species threatened in the wild, is enormous. This was evident from the records of successful captive births of the four selected mammalian species, (Cervus eldi eldi, Macaca silenus, Panthera tigris and Trachypithecus johnii). Selection was based on: IUCN Red List status of the species, inclusion of representatives of important orders and distribution of the species in the country. Results show that zoos in India concentrate largely either on those species which are at a lower risk of extinction in the wild or on large bodied mammals like Panthera tigris, which are difficult to reintroduce into the wild. This is not in accordance with the IUCN Policy Statement on captive breeding. There are lacunae in the areas of prioritisation of Indian taxa for conservation breeding and in the formulation of zoo policy. This has consequently restricted, in many ways, the extent of zoo contribution to the conservation cause. Recommendations have been suggested based on the results that can improve the potential of the zoo to perform its multifaceted role. These include:

* recognising the importance of enclosure enrichment in stimulating physiological and psychological development, which are essential in reintroducing animals to their natural environment

* immediate formulation of a zoo policy

* prioritisation of Indian taxa for conservation breeding

* more attention on smaller bodied mammals like the rodents and bats, which are easier to reintroduce without compromising on visitor appeal

* a re-evaluation of the zoos raison d'être
\end{abstract}

\section{Key words}

AAZP, zoo, conservation, mammals, captive breeding, zoo policy

\section{Introduction}

With accelerating destruction of the worlds wildlife and wildlands, gene pools are becoming fragmented and diminished into gene puddles (Foose, 1983). It has been estimated that 20 per cent or more of the world's biodiversity may disappear in the next few decades, primarily due to habitat fragmentation and alteration. It is therefore necessary that more and more people and institutions become involved in efforts to conserve our imperilled environment. This is where professionally managed zoos and aquariums come into play. Zoos and aquariums assist wildlife in many ways. Although captive breeding should not be considered as the sole solution to the problem of declining

Received 12 September 1998;
Accepted 28 November 1999 species, conservationists have recognised the need for scientifically managed captive breeding programmes in carefully selected areas.

If one were to trace the history of zoos, it is one of bringing exotic animals into captivity to serve human needs for entertainment and education. In recent years, many zoological institutions have re-evaluated their mission with conservation through captive breeding emerging as the basis on which their continuing existence is legitimised. In reality, this shift in mission has been unavoidable, as commerce in exotics has become severely restricted (Else \& Lee, 1986). Faced with reduced augmentation of captive stock through continued harvesting of wild populations, the future of zoos depends increasingly upon 


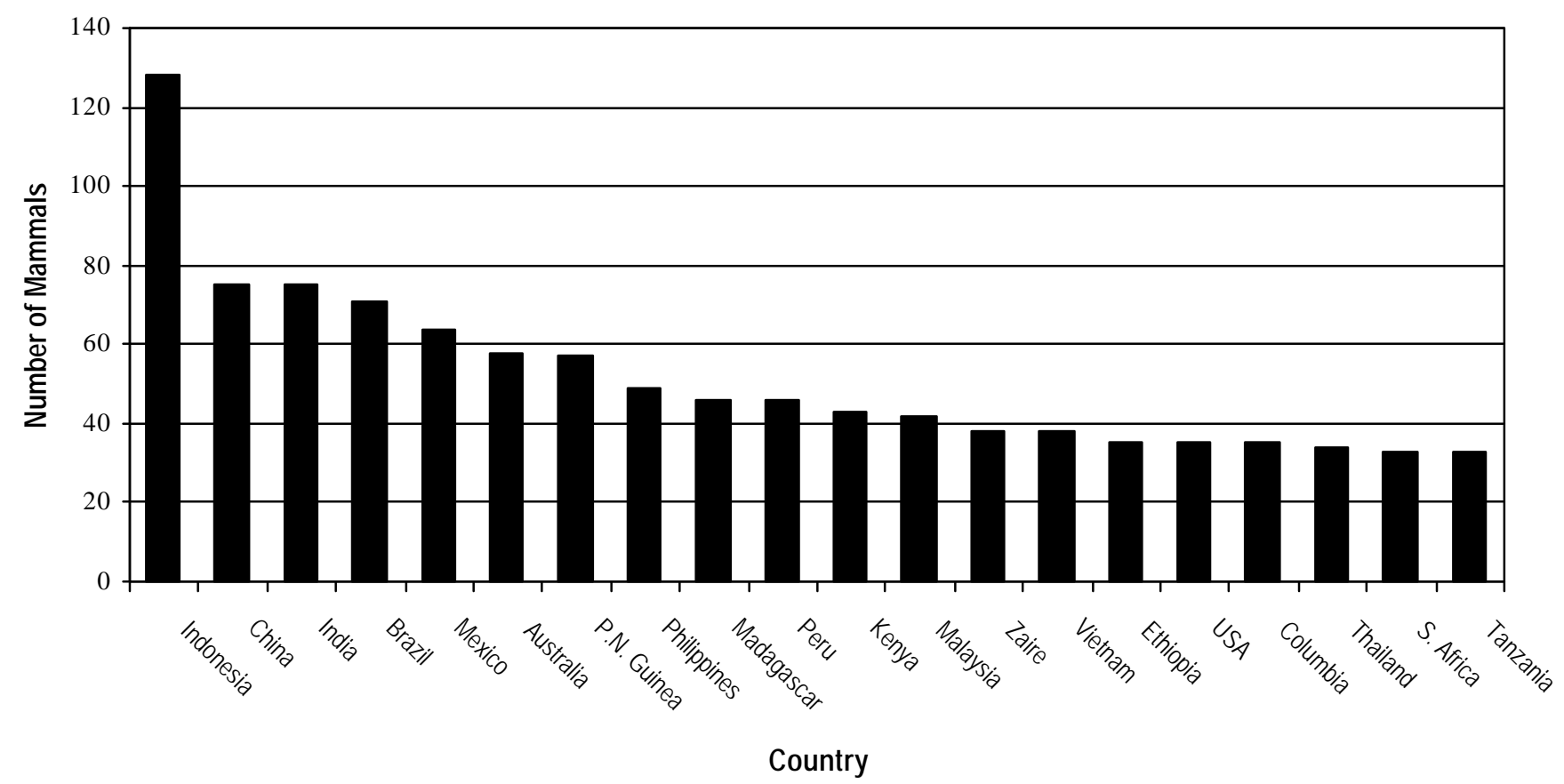

Figure 1. Countries containing the highest numbers of IUCN threatened mammal species. India ranks second along with China (75 species) in the list (IUCN, 1996).

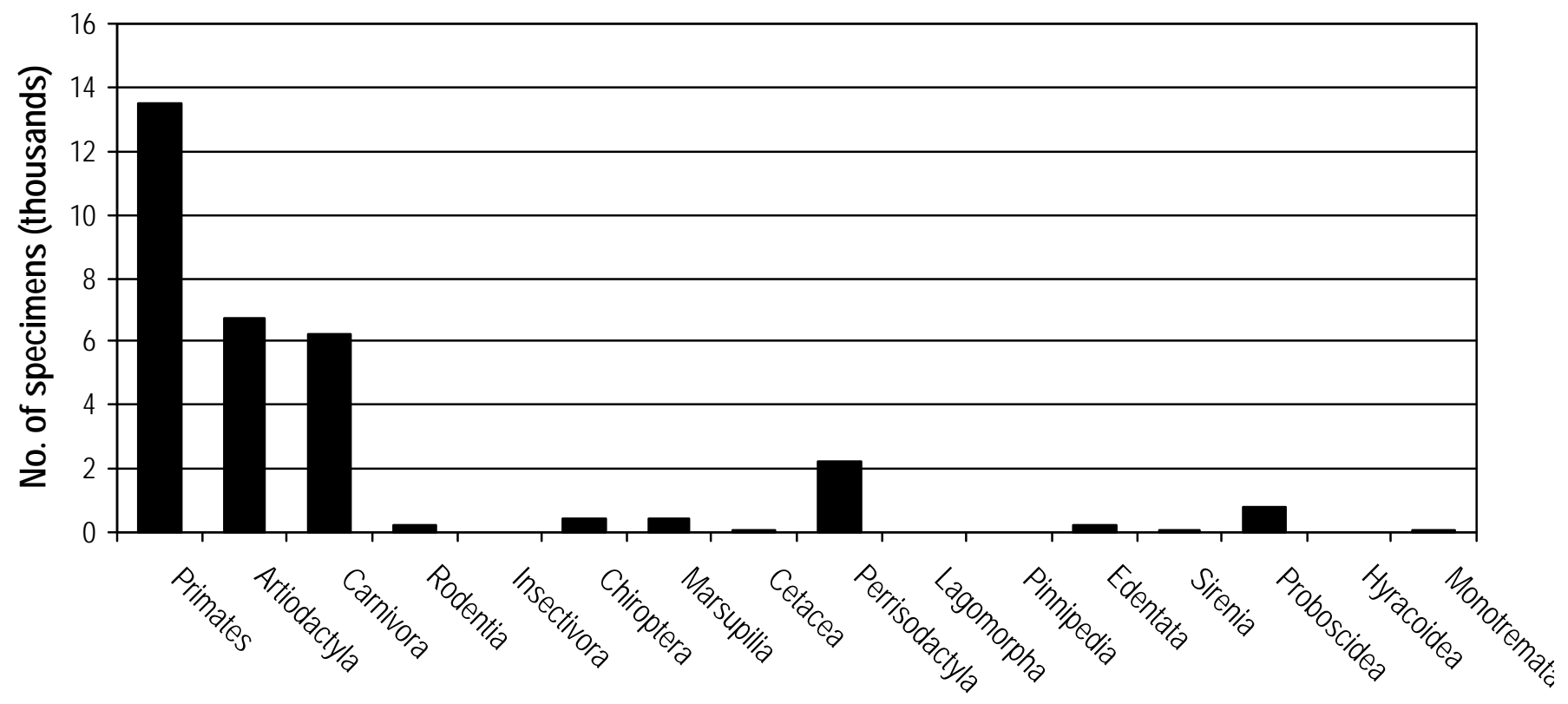

Order

Figure 2. Number of specimens of IUCN threatened mammalian taxa held in captivity. Only 50 per cent of threatened primates, artiodactyla and carnivora are represented (Magin et al., 1994). 


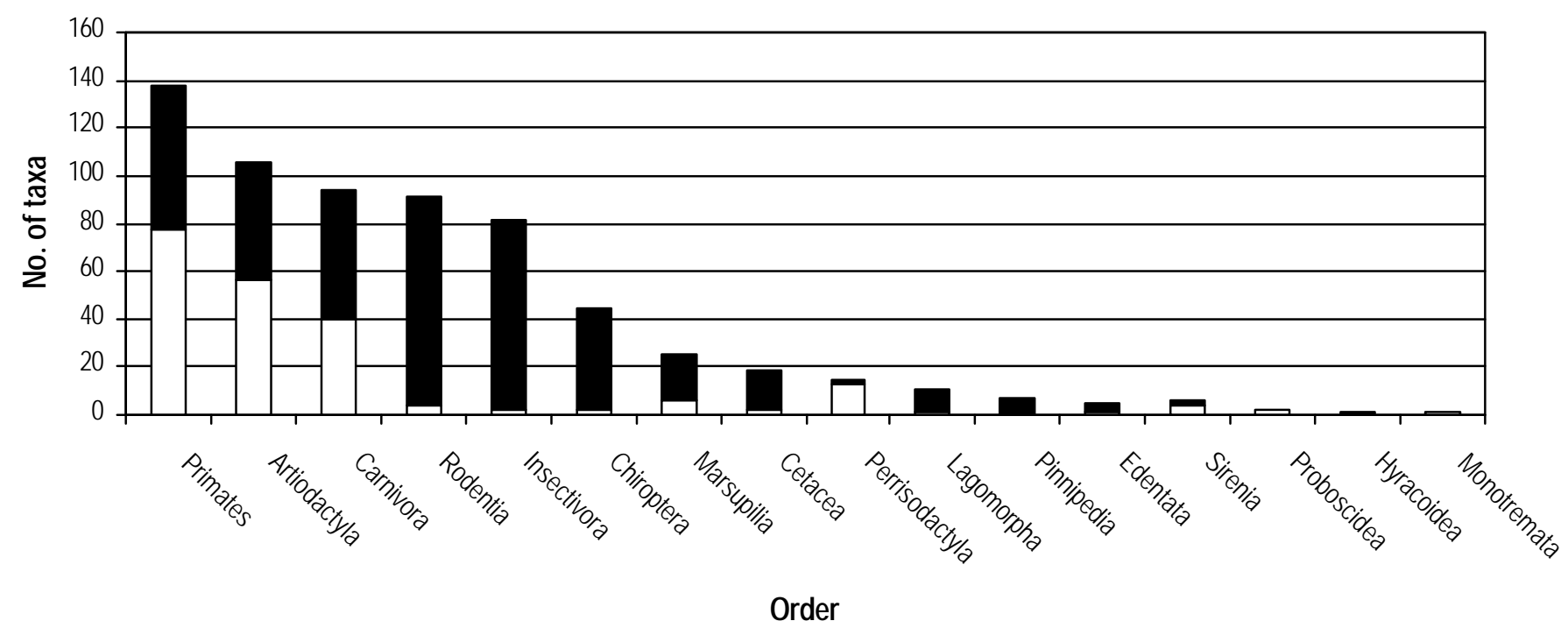

$\square$ Not held in captivity $\square$ Held in captivity

Figure 3. The numbers of IUCN threatened mammalian taxa held in captivity are indicated (Magin et al., 1994). Orders consisting of smaller mammals like Rodentia are poorly represented.

the development of self-sustaining captive populations from brood stock on hand (Else \& Lee, 1986). Survival of many taxa depend on the interactive management of both wild and captive populations. Moreover, as wild populations are reduced and fragmented, captive collections and zoo facilities are becoming larger, more naturalistic and better co-ordinated. Wild and captive populations are converging in terms of the kinds of management that must be employed for their survival (Foose, 1983).

In addition to the above, zoos can act as demographic and genetic reservoirs from which infusions of "new blood" may be obtained or new populations founded (Conway, 1980). Finally, zoos have at last conveyed the message that ultimately they may provide the last refuge for many species of animals which face extinction in the wild. The gulf that exists between conservationists concerned with the wild and those involved in captive breeding will have to be bridged to meet the challenge of the diminishing wild in order that strategies may be developed to prevent the slide into extinction of some selected species (Rawlins, 1985).

\section{Global geographic distribution of zoos and aquaria}

There are approximately 1150 zoos, aquaria and affiliated captive breeding facilities worldwide of which 878 reported their addresses to the International Zoo YearBook. At least 83 countries possess one or more of these institutions (Magin et al, 1994).

\section{Aims of the study}

The study was conducted at Arignar Anna Zoological Park, Vandalur, Chennai, during the period between December 1997 and April 1998. It focused on the following aspects of captive breeding:

- Analysis of the composition of total mammalian species housed at the zoo and comparison with the IUCN Policy Statement on captive breeding.

- Trends in captive births at the study site and their contribution to the conservation scenario.

- Enclosure enrichment, food in captivity and their relevance to the physical/physiological well-being of the animals.

\section{Study Site}

The Madras Zoo was one of the first zoos in India started during the year 1855. The Government of Tamil Nadu decided to create a modern zoological park in the Vandalur Reserve Forest area under the control of the forest department. So, the old zoo was shifted to Vandalur and its new incarnation began. This is one of the biggest zoos in Asia extending to an area of 510 ha. The existing landscape has been utilised as it is and all the animals are exhibited in large open moated island type of enclosures with simulated conditions.

\section{Location}

Arignar Anna Zoological Park is situated in Chengalpettu District on the southern Trunk Road between Chennai and Chengalpettu. It is $32 \mathrm{~km}$ south of Chennai and $22 \mathrm{~km}$ north of 
Table 1. Information on species under study

\begin{tabular}{lllll}
\hline Species & IUCN Status & Order & Family & Distribution \\
\hline Antilope cervicapra & LR-lC & Artiodactyla & & All over the Indian plains \\
Cervus eldi eldi & CR & Artiodactyla & Cervidae & Keibul Lamjao National Park, Manipur \\
Macaca silenus & EN & Primates & Ceropithecidae & Western Ghats \\
Panthera tigris & EN & Carnivora & Felidae & All over India except NW \\
Trachypithecusjohnii & VU & Primates & Ceropithecidae & Westernghats \\
\hline
\end{tabular}

Chengalpettu.

\section{Vegetation type}

Habitat of the park comes under the tropical dry evergreen scrub, a degraded forest mostly comprising thorny bushes.

\section{Methodology}

Criteria for choice of species

The five mammalian species chosen for the study are Antilope cervicapra (Blackbuck), Cervus eldi eldi (Sangai), Macaca silenus (Lion-tailed Macaque), Panthera tigris (Indian Tiger) and Trachypithecus johnii (Nilgiri Langur)

The criteria based on which the selection of the species were made are:

- Each of the chosen species belong to different IUCN categories.

- Representatives of important families and orders are represented here. Some species are restricted to parts of India with respect to distribution while the others are more commonly found in areas distributed in most parts of the country.

\section{Data collection}

Data was collected from the following sources using the following methods:

Studbook information: Every individual species housed in the zoo is enlisted in the studbook. It gives information on sex, date of birth/date of arrival, name, origin, name of sire/dam if captive born etc.

Animal history sheets: In addition to the studbook information it gives an idea on the general health of the animal, relevant medical treatments if any, comments on general behaviour, etc. On-field observations: This included observations of enrichment of the various enclosures, interaction between the animals at feeding times, etc.

Interaction with animal keepers: This helped establish the identity of certain animals. This was important in interpreting observations on dominance, social behaviour etc. especially among the primates.

\section{Results and discussion}

The total number of mammalian species at AAZP is 46, of which 11 are exotics (non-native species) and are not included in the

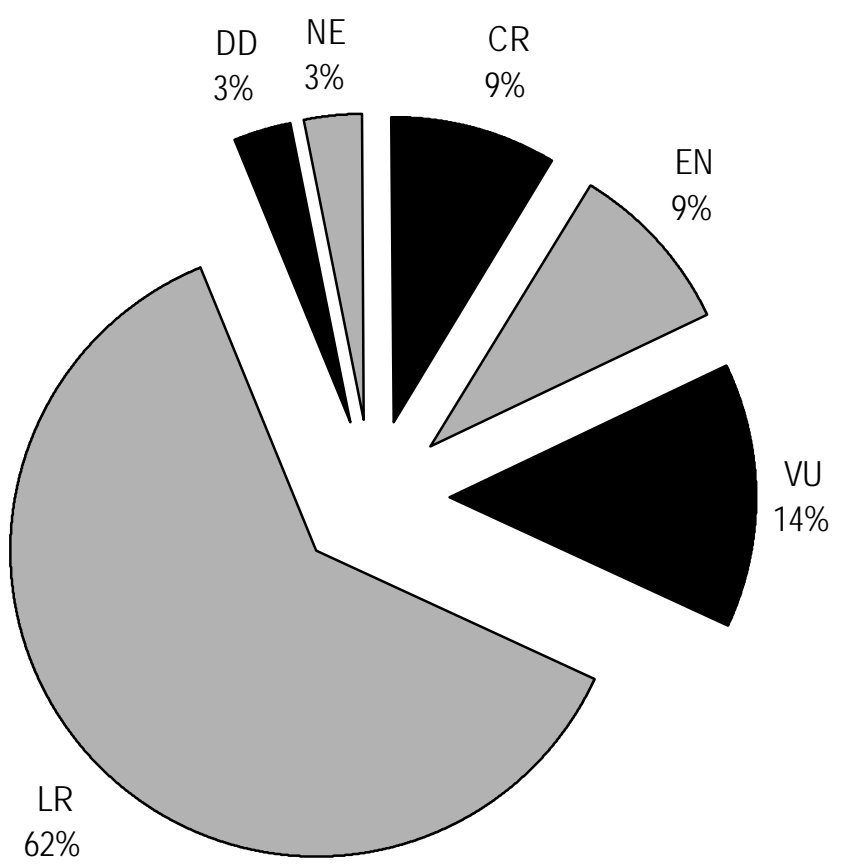

Figure 4. Per cent composition of total mammalian species at $A A Z P$, excluding exotics (CR = Critically Endangered, $E N=$ Endangered, $\mathrm{VU}=$ Vulnerable,$L R=$ Lower Risk, NE = Not Evaluated, $D D=$ Data Deficient)

analysis. A break up of these species based on IUCN criteria (Fig. 4) as derived by Indian field biologists at an Indian Mammal Consevation Assessment and Management Plan workshop (Molur et al., 1998) shows that 62 per cent of the mammals in the Zoo belong to one of the Lower Risk categories while only 32 per cent come under a threatened category $(\mathrm{CR}=9 \% ; \mathrm{EN}=9 \%$; $\mathrm{VU}=14 \%)$. Of the total mammal species kept at the zoo $(\mathrm{n}=46)$, exotics comprise 24 per cent.

The IUCN Policy Statement mentions the following criteria for prioritisation of captive breeding in zoos:

- Increased efforts towards breeding and housing local animals.

- Least expenditure on procurement of exotics. 


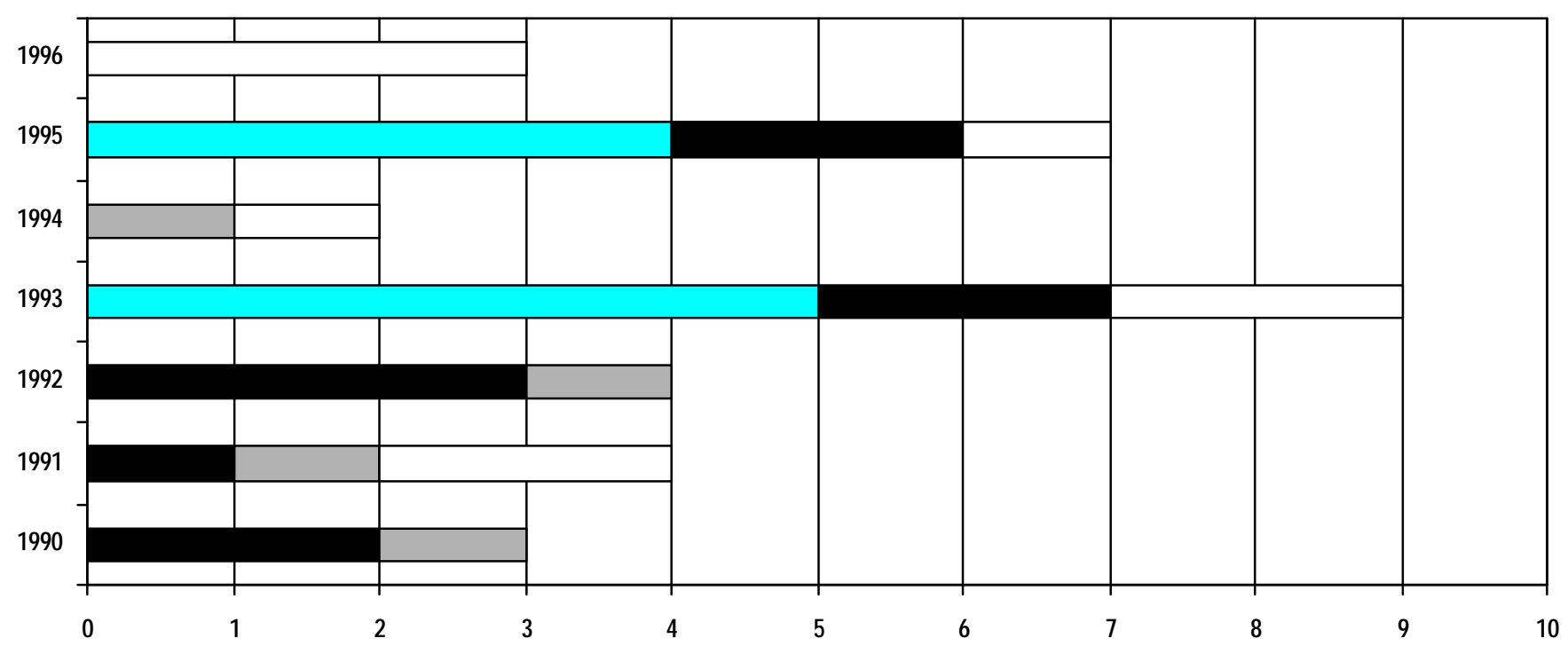

Tiger $\square$ LTM $\square$ Sangai $\square$ N. Langur

Figure 5. Total individual births of the four chosen species at AAZP, Vandalur

- Greatest efforts towards conservation of species belonging to the threatened category.

The results of Fig. 4 evidently are contrary to this, suggesting that the focus of the AAZP is largely restricted to exhibitionism which is controlled by visitor appeal, rather than in conservation of threatened species.
Trends in deaths and births from 1990 to 1996

Results from Figures 5 and 6 show fluctuating trends in both births and deaths of the animals studied. Comparison with data from other prominent zoos in India supported this trend (Courtesy: CZA database). However, the results seem to indicate 1994 as a problem year with not as many births as could be

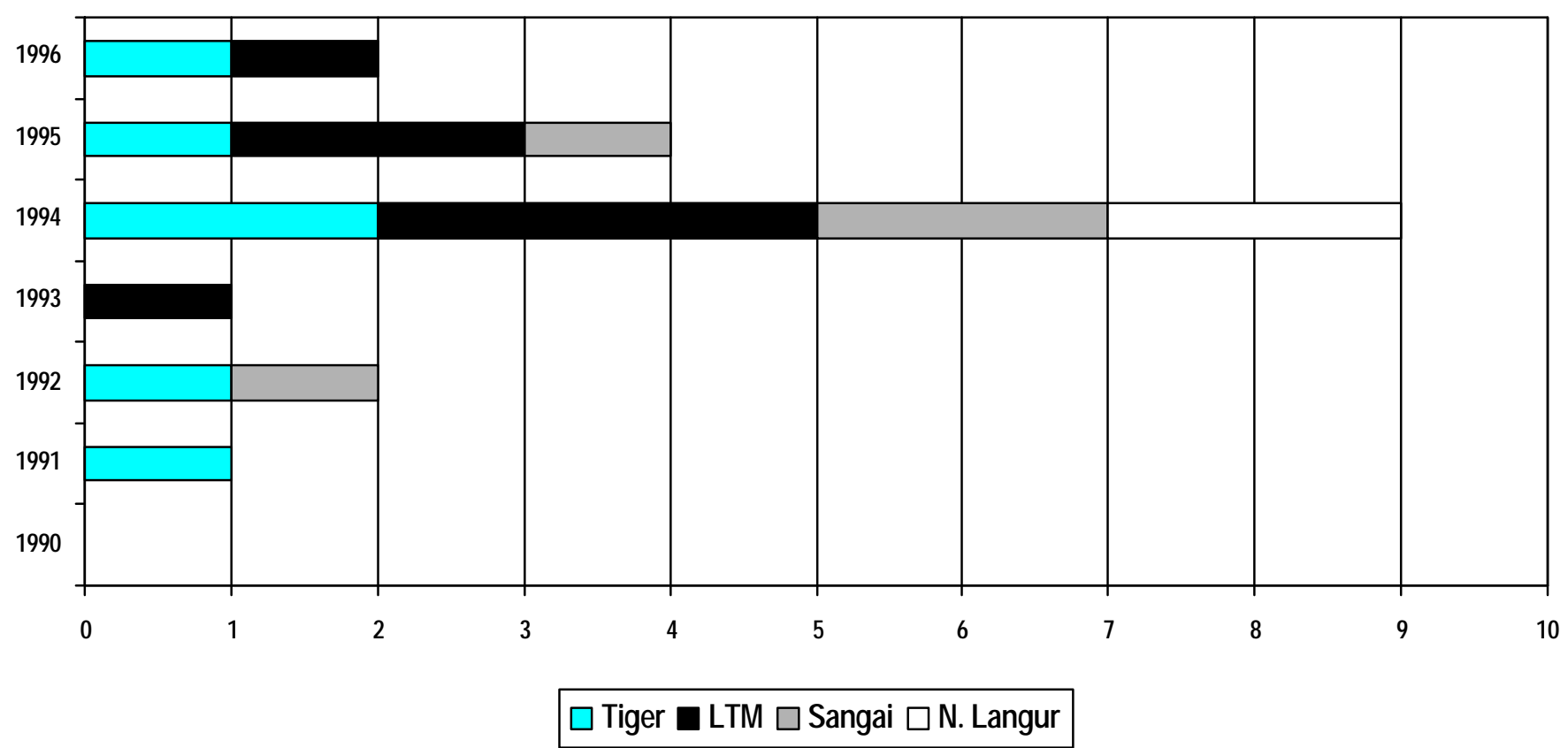

Figure 6. Total individual deaths of the four chosen species at AAZP, Vandalur 
expected, but with a considerably high death toll. Investigations revealed varying causes:

Environmental: There were heavy rains in 1994, which resulted in deaths of animals belonging to many species.

Management related: Example: Introduction of a new individual (LTM) into a well established group showing all signs of a strong pack order, resulted in death due to infighting.

Medical: Possibly better care exists, that was unavailable in the previous and forthcoming years than the year in question

Another reason for zoo deaths is the condition of animals obtained by zoo exchange programmes. A sick animal may not appear physically sick until the last stages of the illness (Manoharan, pers. comm.). There have been instances where animals brought into the zoo by exchange have died as a result of illness contracted earlier. This, coupled with stress endured during the course of transfer, takes a toll on the animals life.

\section{Success of captive propagation at AAZP with respect to the species studied}

Figure 7 conveys information regarding the potential of a zoo to contribute to conservation through captive breeding. The trend of the success rate of captive births at AAZP was compared with relevant data from other prominent zoological institutions in the country. The data on these other institutions was obtained from the Central Zoo Authority's Annual Report on Breeding in Zoos across Indian cities. The comparison showed equal or more often, fewer captive births of the species selected for this study in the other institutions. This leads to the conclusion that when compared with some prominent zoos, the number of captive births at AAZP is higher, with respect to the species chosen.

\section{Observations on enclosures}

LTM enclosure: Visual observation of this enclosure and its animals was compared with the sole reference on enclosure enrichment at AAZP (Ponnuswamy \& Paulraj, 1990). The enclosure has many trees and a lot of vegetation which helps the animals spend a great deal of time foraging for fruits etc., as they would in the wild. The moats are well watered with abundant fish. The vegetation and the water in the moats attract a lot of insects which form a part of the LTM's diet (Ponnuswamy \& Paulraj, 1990).

Blackbuck enclosure: Blackbucks have been shifted from the enclosure originally built for them. Though it encompasses a large area which meets their physical requirement, herbs and shrubs which are an important aspect of enrichment (Ponnuswamy \& Paulraj, 1990) are noticeably absent. Due to limited foraging the animals appear restless.

The number of blackbucks has grown uncontrollably, leading to competition for food. Older and larger animals dominate at feeding times. Free access of this enclosure to the neighbouring Cheetal enclosure puts added pressure during mealtimes with the Cheetals intruding into Blackbuck territory.

Nilgiri Langur: The enclosure is similar to that of the LTM. Larger
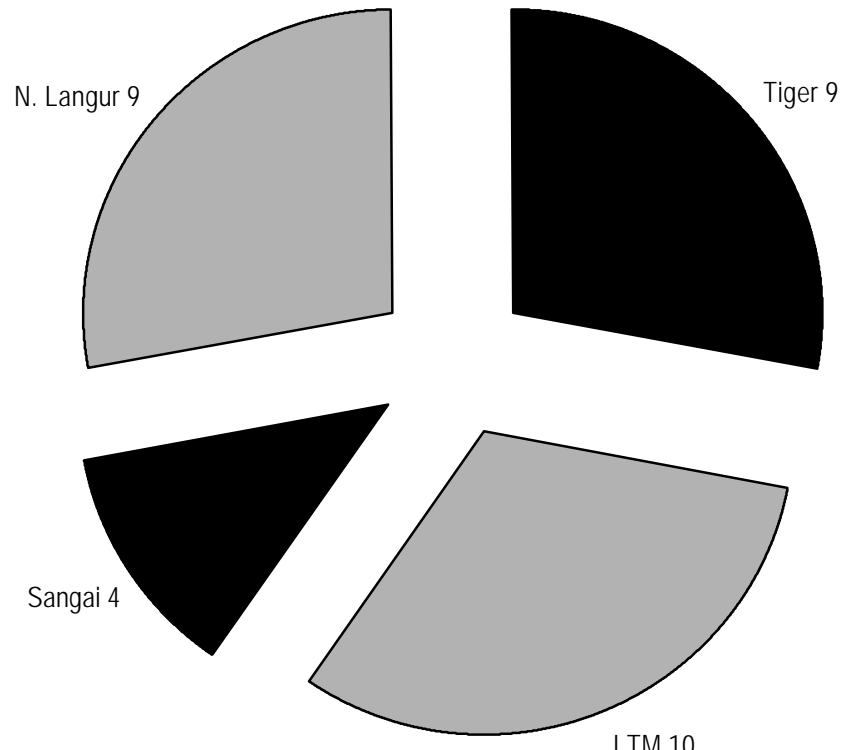

Figure 7. The success of captive propagation at AAZP.

shrubs and trees are present here as the Nilgiri Langur spends longer time on the trees and tree tops.

\section{Conclusion}

The contribution of zoos to conservation via captive breeding is important especially for species which are threatened in the wild. However, most zoos today concentrate on either large bodied mammals and/or on Lower Risk species as was found in this study. The problems associated with maintaining largebodied mammals are higher per capita costs, greater space requirements, lower breeding potential, greater difficulty in reintroduction. More than 30 of the 46 mammalian species at AAZP are large bodied. This scenario is not optimum for the efficient use of resources because of the above reasons (Balmford et al., 1996), as well as the following.

The next rational step after successful captive breeding programmes is reintroduction (Wilson \& Price, 1994). Small bodied mammals as compared to large bodied mammals are better breeders, less expensive to maintain, both in zoo resources and space. Perhaps, most importantly, many are easier to reintroduce. (Balmford et al., 1996). The problems of reintroducing a large bodied carnivore like the tiger or a large herbivore like the elephant have been debated for a long time. Tigers can turn into man eaters or can target livestock as easy prey, while elephants are notorious for aggression and destroying property. The possibility of such threats to human life and the magnitude of threats to property posed by the reintroductions of smaller mammals such as rodents and bats for instance are very minimal. 
Of all Indian mammals, 60 percent are bats and rodents -- all small bodied mammals (Molur et al., 1997). This leads one to emphasise on the importance of prioritisation of Indian taxa for conservation breeding by Indian zoos. It is time that zoos start concentrating on the economic and the biological realities of captive breeding.

Enclosure enrichment and the correct diet in captivity are important factors which influence the success of captive births in a zoo. Stress related with improper enclosure design has been known to affect the breeding potential of the animal.

The potential is evident from the records of successful captive births at AAZP. In order to maximise the contribution of zoos towards conservation, there is an immediate need for policy formulation. This involves selection of criteria with respect to captive breeding in such a way that the zoo is able to juggle between its dual roles of maintaining 'visitor appeal' as well as conservation objectives. The need to focus on species which have long stood neglect has emerged as a priority as well. Maintaining visitor appeal may not be so difficult as it is not necessarily only the larger animals that can fascinate visitors in a zoo. Studies have shown that though large, charismatic taxa such as the big cats, elephants etc. are important in drawing visitors to the zoo, imaginative exhibits of small-bodied taxa are equally popular once they enter. In some cases small creatures have even been effective in increasing zoo attendance (Balmford et al., 1996). Other studies have also proved that there is no tendency for those exhibits with larger mammals to be more popular with the visitors (Balmford et al., 1996). Thus more attention can be directed towards the smaller bodied mammals without compromising on visitors appeal. The second task is more difficult to achieve. A correct balance of a much needed formulation of zoo policy along with economical and biological foresight with respect to captive breeding ought to be able to strengthen the zoos contribution to conservation.

\section{References}

Balmford, A., G.M. Mace and N. Leader-Williams (1996). Designing the Ark: Setting priorities for Captive Breeding. Conservation Biology 10(3): 719-727.

Conway, W.G. (1980). An Over-view of captive propagation. In Conservation Biology - an evolutionary-ecological perspective, M.E. Soule, B.A. Wilcox (eds). Sinauer Associates Inc., pp 199-208.

Else, J.J. and P.C. Lee (1986). Primate Ecology and Conservation. Cambridge University Press, pp 295-300, 344-351.

Foose, T.J. (1983). Relevance of captive populations to conservation of biodiversity. In: Genetics and conservation: a reference for managing wild animal and plant populations, C.M. Schonewal-Cox, S.M. Chambers, B. MacBryde (eds). Benjamin Cummings Publishing Company Inc., pp 374-401.

IUCN (1996). 1996 IUCN Red List of Threatened Animals. IUCN, Gland, Switzerland and Cambridge, UK. 448pp.

Magin, C.D., T.H. Johnson., B. Groombrideg., M. Jenkins and H. Smith (1994). Species extinctions, endangerment and captive breeding. In: Creative Conservation - interactive management of wild and captive animals, P.J.S. Olney, G.M. Moore, A.T.C. Feistner (eds). Chapman and Hall, pp 3-30.

Molur, S., P.O. Nameer and Sally Walker (1998). Report mof the workshop "Conservation Assessment and Management Plan for Mammals of India" (BCPP - Endangered Species Project), Zoo Outreach Organisation, Conservation Breeding Specialist Group, India. 35-38

Ponnuswamy, K.P. and S. Paulraj (1990). Environmental enrichment of zoo enclosures- pre-requisite for captive breeding of endangered species. Zoo's Print 5(3): 17-20.

Rawlins, C.G.C. (1985). Zoos and conservation - the last 20 years. In Advances in Animal Conservation, J.P. Hearns, J.K. Hodges (eds). Oxford University Press, pp 59-69.

Wilson, A.C. and M.R. Stanley Price. (1994). Reintroduction as a reason for captive breeding. In: Creative Conservation - interactive management of wild and captive animals, P.J.S. Olney, G.M. Moore, A.T.C. Feistner (eds). Chapman and Hall, pp 243-261. 